\title{
Benchmarking the new ENDF/B-VIII.0 nuclear data library for the first core of Indonesian multipurpose research reactor (RSG GAS)
}

\author{
Donny Hartanto ${ }^{1, *}$, Victor Gillette ${ }^{1}$, Tagor Malem Sembiring ${ }^{2}$, and Peng Hong Liem ${ }^{3,4}$ \\ ${ }^{1}$ University of Sharjah, United Arab Emirates \\ ${ }^{2}$ National Nuclear Energy Agency (BATAN), Indonesia \\ ${ }^{3}$ Tokyo City University, Japan \\ ${ }^{4}$ Nippon Advanced Information Service (NAIS Co., Inc.), Japan
}

\begin{abstract}
The Indonesian Multipurpose Research Reactor namely Reaktor Serba Guna G.A. Siwabessy (RSG GAS) is a $30 \mathrm{MWth}$ (max.) pool-type reactor loaded with plate-type low-enriched uranium fuel, using light water as coolant and moderator, and beryllium as reflector. The benchmark of the 1st criticality core of RSG GAS using different nuclear data libraries such as JENDL-4.0, JENDL-3.3, ENDF/B-VII.0, and JEFF-3.1 have been performed in the previous work and compared with the experiment result. In this work, the newly released ENDF/B-VIII.0 neutron reaction and thermal neutron scattering libraries will be used and the important neutronics parameters such as multiplication factor, kinetics parameters, and fission reaction rate will be calculated using Monte Carlo code MCNP6.2 and compared against the previous work and the experiment result.
\end{abstract}

\section{Introduction}

In early 2018, a new version of the ENDF/B nuclear data library, ENDF/B-VIII.0, has been released [1]. Compared to its predecessor, ENDF/B-VII.1, the new version has neutron cross section library for 557 isotopes and thermal scattering law library for 34 materials, while the neutron cross section and thermal scattering law libraries of ENDF/B-VII. 1 cover 423 isotopes and 21 materials, respectively.

In this study, the new ENDF/B-VIII.0 is applied into the Indonesian Multipurpose Research Reactor benchmark since there are major changes in the neutron cross section library of several isotopes used in the reactor such as ${ }^{1} \mathrm{H},{ }^{9} \mathrm{Be},{ }^{56} \mathrm{Fe},{ }^{235} \mathrm{U}$, and ${ }^{238} \mathrm{U}$ [1]. The calculation has been performed by using the continuous-energy Monte Carlo MCNP6.2 code [2]. The results are then compared to the available experiment results for the effective neutron multiplication factor $\left(k_{e f f}\right)$ and the control rod worth. Meanwhile the neutron spectra, kinetics parameters, and the fission rate distribution of RSG GAS first core using ENDF/B-VIII.0 are also compared with the previous studies [3-5] which also have been performed by using MCNP6 in conjunction with previous version of nuclear data libraries such as ENDF/B-VII.1 [6] and JENDL-4.0 [7].

\section{Description of RSG GAS}

The Indonesian multipurpose research reactor, Reaktor Serba Guna G.A. Siwabessy (RSG GAS) is a berylliumreflected, light-water-moderated and -cooled, $30 \mathrm{MWth}$

*e-mail: dhartanto@sharjah.ac.ae (max.) pool-type reactor. The first criticality of the reactor was achieved in 1987. Reactor main data is shown in Table 1. Fuel elements (FEs) are plate-type, and each consists of 21 fuel plates assembled by two side plates. One fuel plate contains $19.75 \%$ enriched uranium oxide meat dispersed in aluminum matrix, and aluminum cladding on both sides of the meat. Control fuel elements (CEs) with identical outer dimension consist of 15 fuel plates, that is, three fuel plates at both outer sides of the fuel elements are removed to provide space for absorber blades. A fork type control rod can be inserted into or withdrawn out of the control fuel element.

The full configuration of the first core of RSG GAS consists of 12 fresh standard and 6 control fuel elements while the configuration for the first criticality needs only fresh 9 standard and 6 control fuel elements. At each loading step, reactivity gains were measured by calibrating the difference of the regulating rod (RR) position with a reactivity meter and it had been corrected by a method described elsewhere [3]. The first criticality and full core configurations of the first core are shown in Figs. 1 and 2, respectively. Meanwhile, Table 2 lists the calculation cases of the first core of RSG GAS.

\section{Results and Discussion}

Before analyzing the results, the calculation model and condition are described here briefly. The RSG GAS first core in this study has been modeled explicitly using MCNP6.2 except for the top and end-fitting regions of the elements, the core grid, and bottom supports in which homogenized mixture models have been used. All components of the core have temperature of $300 \mathrm{~K}$. The number 


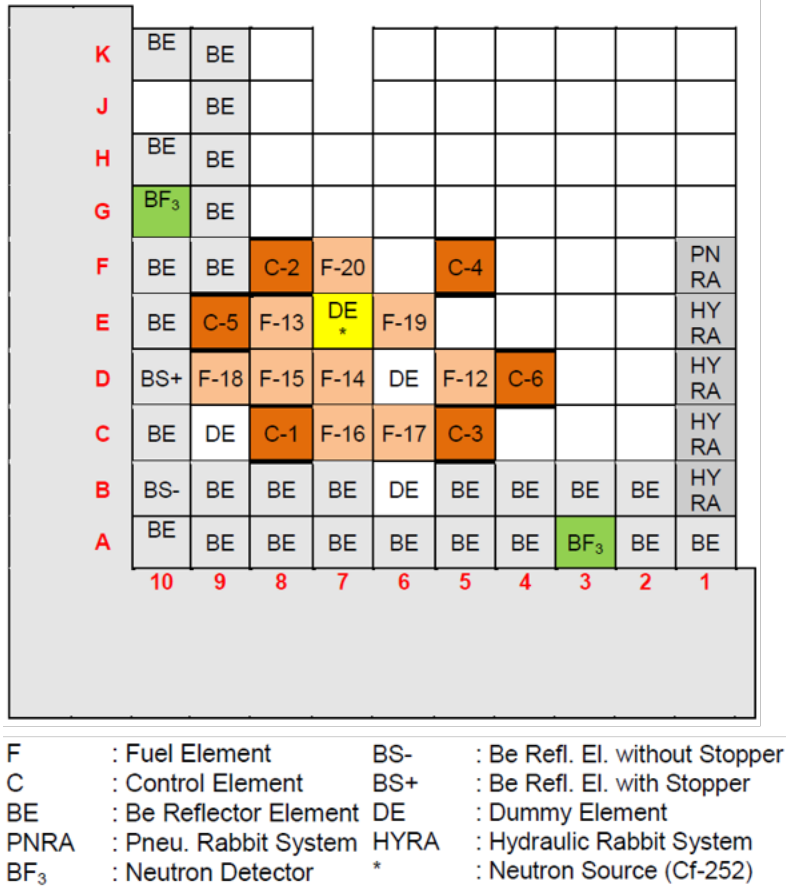

Figure 1. First criticality core configuration of RSG GAS first core [3]

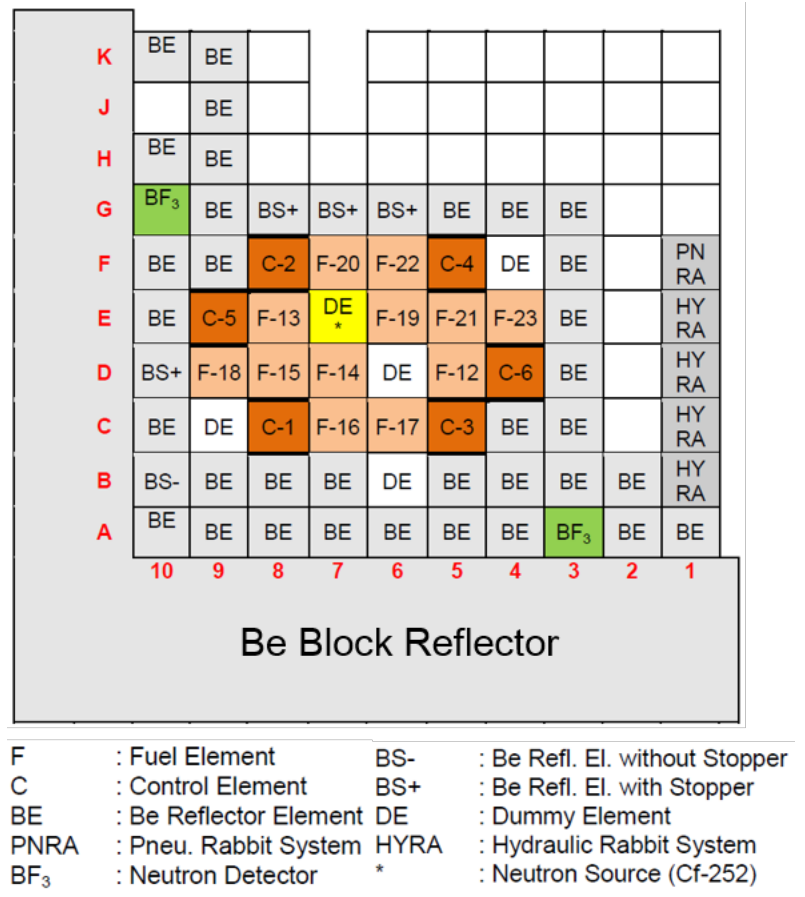

Figure 2. Full core configuration of RSG GAS first core [3]

of the neutron histories per cycle is 400,000 and the total number of cycles is 2,000 with 200 inactive cycles. With the given calculation conditions, the standard deviation of $k_{\text {eff }}$ values is less than $5 \mathrm{pcm}$. The thermal scattering libraries for light water and metal beryllium are also used.

The first result is shown in Fig. 3, which is the comparison of the $k_{\text {eff }}$ between the experimental results and the Monte Carlo calculation results using different nu-
Table 1. Design Parameters of RSG GAS [3]

$\begin{array}{ll} & \text { General } \\ \text { Reactor type } & \\ \text { Fuel element type } & \text { Pool type } \\ \text { Cooling system } & \text { LEU oxide MTR } \\ & \text { Forced convec- } \\ & \text { tion } \\ \text { Moderator/coolant } & \text { Down Flow } \\ \text { Reflector } & \mathrm{H}_{2} \mathrm{O} \\ \text { Maximum power (MWth) } & \mathrm{Be} \text { and } \mathrm{H}_{2} \mathrm{O} \\ & 30\end{array}$

Core Characteristics (full core configuration)

No. of fuel elements $\quad 40$

No. of control elements 8

No. of fork type absorbers (pairs) 8

Nominal cycle length (fpd) 25

Avg. burn-up at BOC 23.3

(\% loss of U-235)

Avg. burn-up at EOC $\quad 31.3$

(\% loss of U-235)

Avg. discharge burn-up at EOC $\quad 53.7$

(\% loss of U-235)

Fuel/control elements

Fuel/control element dimension $77.1 \times 81 \times 60$

(mm)

Fuel plate thickness (mm) $\quad 1.3$

Coolant channel width $(\mathrm{mm}) \quad 2.55$

No. of plate per fuel element 21

No. of plate per control element 15

Fuel plate clad material $\quad \mathrm{AlMg}_{2}$

Fuel plate clad thickness (mm) $\quad 0.38$

Fuel meat dimension $(\mathrm{mm}) \quad 0.54 \times 62.75 \times 600$

Fuel meat material $\quad \mathrm{U}_{3} \mathrm{O}_{8} \mathrm{Al}$

U-235 enrichment (w/o) $\quad 19.75$

Uranium density in meat $(\mathrm{g} / \mathrm{cc}) \quad 2.96$

U-235 loading per FE $(\mathrm{g}) \quad 250$

U-235 loading per CE $(\mathrm{g}) \quad 178.6$

Absorber meat material Ag-In-Cd

Absorber thickness (mm) $\quad 3.38$

Absorber clad material $\quad$ SS-321

Absorber clad thickness (mm) $\quad 0.85$

clear data libraries. It is shown that agreement among the 3 nuclear data libraries is excellent, and ENDF/B-VIII.0 library consistently provides slightly higher values than ENDF/B-VII.1 and JENDL-4.0 libraries. In overall, the calculation values by MCNP6.2 are slightly higher than the experimental results. The highest overestimation from the experiment result (about $0.95 \% d k$ ) is observed for the full core configuration when all control rods are withdrawn. However, it should be mentioned that the value of the $k_{\text {eff }}$ at the full core configuration was not purely experimental data. The data recorded for this core configuration was given in unit of $\$$ and then it was converted to $k_{\text {eff }}$ using the computed total effective delayed neutron fraction $\left(\beta_{e f f}\right)$ by Monte Carlo method [4] since there was no measured data available for $\beta_{e f f}$. In addition, the $k_{e f f}$ 
Table 2. Calculation cases of RSG GAS first core

\begin{tabular}{|c|c|}
\hline \multicolumn{2}{|l|}{ First Group } \\
\hline $\begin{array}{l}\text { First criticality and excess reactivity } \\
\text { loading }\end{array}$ & Remarks \\
\hline $\begin{array}{l}\text { First criticality ( } 9 \text { FEs, } 6 \text { CEs, } R R=475 \\
\mathrm{~mm} \text { ) }\end{array}$ & Critical \\
\hline Full core (12 FEs, 6 CEs, CRs all up) & Supercritical \\
\hline $\begin{array}{l}\text { Full core (12 FEs, } 6 \text { CEs, CRs all } \\
\text { down) }\end{array}$ & Subcritical \\
\hline \multicolumn{2}{|l|}{ Second Group } \\
\hline $\begin{array}{l}\text { Calibrated rod/grid position (Cali- } \\
\text { brated rod position/other rod bank } \\
\text { position }\end{array}$ & Remarks \\
\hline JDA06/C-8 (600 mm/290 mm) & Critical \\
\hline JDA01/E-9 (600 mm/284 mm) & Critical \\
\hline JDA03/F-8 (600 mm/293 mm) & Critical \\
\hline JDA05/C-5 (600 mm/288 mm) & Critical \\
\hline JDA04/F-5 (600 mm/290 mm) & Critical \\
\hline JDA07/D-4 (600 mm/282 mm) & Critical \\
\hline
\end{tabular}

(the excess reactivity) was evaluated by simply summing up the individually measured control rod reactivity, therefore control rod interference was neglected.

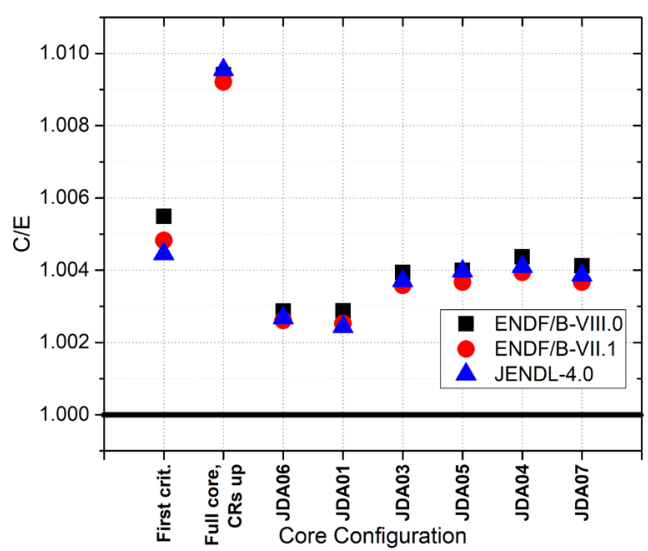

Figure 3. $\mathrm{C} / \mathrm{E}$ of $k_{\text {eff }}$ for different nuclear data libraries

In order to get a better understanding on the impact of the new ENDF/B-VIII.0 library, the sensitivity of the specific isotope neutron cross section from ENDF/B-VIII.0 to $k_{\text {eff }}$ is also studied and shown in Fig. 4. The calculation was performed for the full core configuration when all control rods are withdrawn and only for several main nuclides in RSG GAS. It is shown that for ENDF/B-VII.1, the maximum reduction on $k_{e f f}$ is given by the ${ }^{16} \mathrm{O}$ (in coolant) followed by the ${ }^{1} \mathrm{H}$ (in coolant), $\mathrm{S}(\alpha, \beta)$ of $\mathrm{H}$ in $\mathrm{H}_{2} \mathrm{O}$, and ${ }^{9} \mathrm{Be}$ of ENDF/B-VIII.0 library, while $k_{\text {eff }}$ increases slightly for the ${ }^{235} \mathrm{U}$ ENDF/B-VIII.0 library. However, it is observed for JENDL-4.0, replacing ${ }^{9} \mathrm{Be}$ and ${ }^{16} \mathrm{O}$ from ENDF/B-VIII.0 decreases $k_{e f f}$, while replacing $\mathrm{S}(\alpha$, $\beta$ ) of $\mathrm{H}$ in $\mathrm{H}_{2} \mathrm{O},{ }^{235} \mathrm{U}$, and ${ }^{238} \mathrm{U}$ from ENDF/B-VIII.0 library increases $k_{\text {eff } f}$. Since the differences are in positive
Table 3. Effective total delayed neutron fractions for different nuclear data libraries

\begin{tabular}{llll}
\hline$\beta_{\text {eff }}[\mathrm{pcm}]$ & $\begin{array}{l}\text { ENDF/B- } \\
\text { VIII.0 }\end{array}$ & $\begin{array}{l}\text { ENDF/B- } \\
\text { VII.1 }\end{array}$ & $\begin{array}{l}\text { JENDL- } \\
4.0\end{array}$ \\
\hline First cricality & $745 \pm 5$ & $743 \pm 10$ & $743 \pm 9$ \\
$\begin{array}{l}\text { Full Core } \\
\text { (CRs all up) }\end{array}$ & $733 \pm 4$ & $732 \pm 9$ & $737 \pm 9$ \\
$\begin{array}{l}\text { Full Core } \\
\text { (CRs all down) }\end{array}$ & $740 \pm 4$ & $759 \pm 11$ & $747 \pm 10$ \\
\hline
\end{tabular}

Table 4. Prompt neutron generation time for different nuclear data libraries

\begin{tabular}{llll}
\hline$\Lambda[\mu \mathrm{s}]$ & $\begin{array}{l}\text { ENDF/B- } \\
\text { VIII.0 }\end{array}$ & $\begin{array}{l}\text { ENDF/B- } \\
\text { VII.1 }\end{array}$ & $\begin{array}{l}\text { JENDL- } \\
4.0\end{array}$ \\
\hline First cricality & $84.16 \pm 0.11$ & $84.55 \pm 0.24$ & $86.76 \pm 0.24$ \\
Full Core & $74.01 \pm 0.07$ & $75.00 \pm 0.19$ & $76.16 \pm 0.18$ \\
(CRs all up) & & & \\
$\begin{array}{l}\text { Full Core } \\
\text { (CRs all down) }\end{array}$ & $67.81 \pm 0.06$ & $68.30 \pm 0.18$ & $69.50 \pm 0.18$ \\
\hline
\end{tabular}

and negative values, it is noticed that $k_{e f f}$ values are similar among the three different nuclear data.

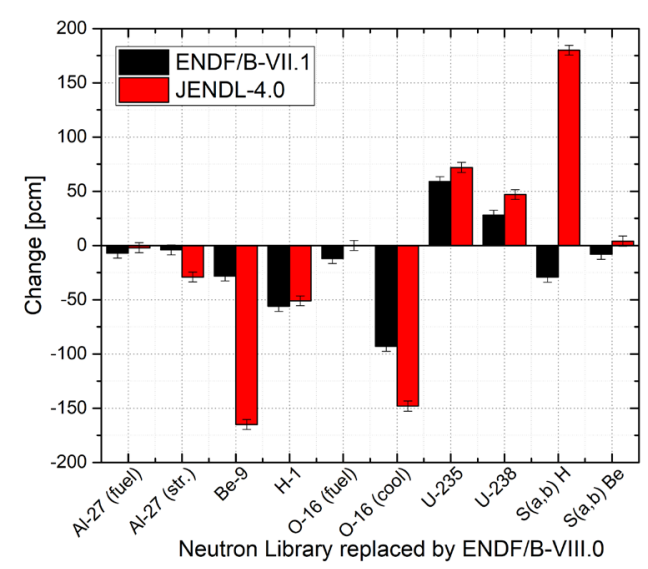

Figure 4. Impact of specific isotope ENDF/B-VIII.0 neutron library on $k_{e f f}$ of other libraries

Tables 3 and 4 summarize calculated kinetics parameters including $\beta_{\text {eff }}$ and $\Lambda$ (prompt neutron generation time) for the 3 core configurations of RSG GAS first core. It should be mentioned that the kinetics parameters were calculated using the adjoint method available in MCNP6. Generally, the value of each parameters at each core configuration is consistent among the 3 nuclear data libraries. However, the value of $\beta_{\text {eff }}$ at the full core configuration when all the control rods are inserted is noticed to be slightly different among the 3 nuclear data libraries. The standard deviation of the previous results is higher for this core configuration and it is recommended to be calculated again using higher neutron histories to reduce the calculation uncertainty.

The control rod worth is compared in Table 5. The worth value for the experiment was the arithmetic summa- 
Table 5. Control rod worth for different nuclear data libraries

\begin{tabular}{llll}
\hline Worth [pcm] & $\begin{array}{l}\text { ENDF/B- } \\
\text { VIII.0 }\end{array}$ & $\begin{array}{l}\text { ENDF/B- } \\
\text { VII.1 }\end{array}$ & $\begin{array}{l}\text { JENDL- } \\
4.0\end{array}$ \\
\hline Exp. & & 17.18 \\
MCNP6 & $17.74 \pm 0.01$ & $17.77 \pm 0.01$ & $17.80 \pm 0.01$ \\
\hline
\end{tabular}

Table 6. Relative fission rate distributions

\begin{tabular}{lll}
\hline Position & $\begin{array}{l}\text { Relative difference } \\
\text { of ENDF/B-VII.1 }\end{array}$ & $\begin{array}{l}\text { Relative difference } \\
\text { of JENDL-4.0 }\end{array}$ \\
\hline C-5 & $-0.31 \%$ & $-0.27 \%$ \\
C-6 & $-0.38 \%$ & $-0.57 \%$ \\
C-7 & $-0.33 \%$ & $-0.33 \%$ \\
C-8 & $-0.44 \%$ & $-0.30 \%$ \\
D-4 & $-0.16 \%$ & $-0.13 \%$ \\
D-5 & $-0.37 \%$ & $-0.59 \%$ \\
D-7 & $-0.50 \%$ & $-0.73 \%$ \\
D-8 & $-0.50 \%$ & $-0.51 \%$ \\
D-9 & $-0.40 \%$ & $0.05 \%$ \\
E-4 & $-0.14 \%$ & $-0.23 \%$ \\
E-5 & $-0.41 \%$ & $-0.61 \%$ \\
E-6 & $-0.52 \%$ & $-0.77 \%$ \\
E-8 & $-0.44 \%$ & $-0.44 \%$ \\
E-9 & $-0.35 \%$ & $0.20 \%$ \\
F-5 & $-0.24 \%$ & $-0.39 \%$ \\
F-6 & $-0.26 \%$ & $-0.25 \%$ \\
F-7 & $-0.31 \%$ & $-0.28 \%$ \\
F-8 & $-0.38 \%$ & $-0.07 \%$ \\
\hline
\end{tabular}

tion of each control rod worth without considering the rod shadowing effect. Due to this, there is a different between experiment and calculated results. However, it is noticed that the worth from the 3 nuclear data libraries concurs.

For the last result, the relative fission rate distributions against ENDF/B-VIII.0 are also compared in Table 6 for the full core configuration with control rods at up position. Good agreement among ENDF/B-VIII.0, ENDF/B-VII.1, and JENDL-4.0 is clearly observed with the relative difference less than $0.77 \%$ at E-6 position.

\section{Conclusion}

The new released ENDF/B-VIII.0 nuclear data library has been used to calculate several important neutronics parameters of Indonesian multipurpose research reactor RSG-GAS. The k-eff maximum error $(\mathrm{C} / \mathrm{E})$ is found to be $0.95 \%$ for the full core configuration when all control rod are withdrawn. For ENDF/B-VII.1, replacing ${ }^{16} \mathrm{O}$ (coolant) from ENDF/B-VIII.0 library provides the largest reduction of k-eff value. For JENDL-4.0, replacing ${ }^{9} \mathrm{Be}$ and ${ }^{16} \mathrm{O}$ (coolant) from ENDF/B-VIII.0 library noticeably decreases k-eff, while replacing libraries of $\mathrm{S}(\alpha, \beta)$ of $\mathrm{H}$ in $\mathrm{H}_{2} \mathrm{O},{ }^{235} \mathrm{U}$, and ${ }^{238} \mathrm{U}$ from ENDF/B-VIII.0 increase k-eff. Meanwhile, important parameters such as $\beta_{\text {eff }}, \Lambda, \mathrm{CR}$ worth, fission rate distribution are consistent and similar among different nuclear data libraries.

\section{References}

[1] D. A. Brown et al., Nucl. Data Sheets 148, 1-142 (2018)

[2] C. J. Werner (editor), MCNP User's Manual Code Version 6.2 (LANL, Los Alamos, 2017) LA-UR-1729981

[3] P. H. Liem and T. M. Sembiring, Ann. Nucl. Energy 44, 58-64 (2012)

[4] P. H. Liem et al., Prog. Nucl. Energy 109, 196-203 (2018)

[5] P. H. Liem et al., Prog. Nucl. Energy 114, 46-60 (2019)

[6] M. B. Chadwick et al., Nucl. Data Sheets 112 (12), 2887-2996 (2011)

[7] K. Shibata et al., J. Nucl. Sci. Technol. 48 (1), 1-30 (2011) 